\title{
Extractivismo y posneoliberalismo: el caso de Ecuador
}

\author{
Verónica Albuja \\ Pablo Dávalos
}

Resumen. En este artículo se analizan las modalidades extractivas del gobierno de Alianza País y Rafael Correa en el periodo 2007-2012. Al considerar el reordenamiento territorial en función de la mercantilización de los territorios y su integración a las dinámicas de la acumulación financiera del capitalismo, comprendemos las formas más visibles del extractivismo: la ampliación de la frontera petrolera, sobre todo la exploración y explotación de petróleo en mar abierto, glaciales, reservas naturales y territorios indígenas; la industrialización de bituminosas y de esquisto; la minería a cielo abierto; el agronegocio que incluye pesticidas, transgénicos, monocultivos y sistemas de plantación; los servicios ambientales (privatización de agua, mercados de carbono, industria del turismo, pago por servicios ambientales); la biotecnología; la geotecnología, los biocombustibles, entre otros.

PAlabras ClAVE: extractivismo, posneoliberalismo, Ecuador, reodernamiento territorial, mercantilización.

Авstract. This article analizes the extractive modalities of the government of Alianza País and Rafael Correa during the period 2007-2012. By considering territorial reorganization as a function of the coomodification of territories and their integration into the dynamics of capitalist financial accumulation, we cover the most visible forms of extractivism: the extension of the petroleum frontier, especially the exploration and explotation of petroleum in the open sea, glaciers, protected areas and indigenous territories; the industrialization of heavy oil and shale; open-pit mining; agribusiness that includes pesticides, transgenics, monocultures and plantation systems; environmental services (the privatization of water, carbon markets, the turism industry, paying for environmental services); biotechnology; geotechnology, biofuels, among others.

KEYWORDS: extractivism, postneoliberalism, Ecuador, territorial reorganization, commodification.

Verónica Albuja es politóloga ecuatoriana y ex asesora de la Confederación de Nacionalidades Indígenas del Ecuador. Pablo Dávalos es economista ecuatoriano. Profesor titular de la Pontificia Universidad Católica del Ecuador. 


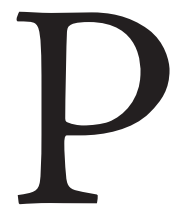

ara comprender el alcance del extractivismo y situarlo de manera coherente al interior de una praxis económica, política e institucional, creemos pertinente proponer una definición más larga que comprenda, al menos, las siguientes dimensiones:

1. El reordenamiento territorial en función de la mercantilización de los territorios y su integración a las dinámicas de acumulación financiera del capitalismo global (Gudynas, 2009; Luxemburg, 1978).

2. La transferencia de decisiones macroeconómicas hacia la inversión extranjera directa y los inversionistas (sobre todo crecimiento económico, inversión y empleo).

3. La geopolítica que integra el extractivismo a los nuevos procesos de lucha por la hegemonía mundial, donde se han intensificado los procesos de concentración y centralización del capital a escala mundial (Petras, 2007).

4. La convergencia normativa hacia las definiciones de la Organización Mundial del Comercio (омс), los tratados de libre comercio y la conformación del inversionista y de la inversión extranjera directa como nuevos sujetos de contractualidad estructurados bajo el Estado de derecho (Dávalos, 2013; Harvey, 2005).

5. El control y disciplina social, en especial por las transferencias monetarias condicionadas y por el uso del gasto fiscal social como legitimador político (Zibechi, 2010).

6. La integración de infraestructuras territoriales en función de la acumulación del capital y la conformación de nuevos bloques de poder (Saltos, 2010; PortoGonçalves, 2009).

7. La nueva arquitectura institucional para la integración política regional que altera los bloques de poder mundial (BRICS, UNASUR, BNDES).

8. La violencia, la criminalización social y el «uso heurístico del miedo» como mecanismo de dominación política, y la resolución de conflictos por los territorios y el control de la sociedad por paramilitares, mafias de narcotráfico y terrorismo (Dávalos, 2011; Figueroa Ibarra, 2011).

9. Sistemas políticos hegemónicos y autoritarios sustentados en mecanismos de elección (democracias disciplinarias, Dávalos, 2010). 
10. La colonización epistemológica en la cual las universidades convergen hacia mecanismos de mercado (Reformas de Bologna) y se articulan formas de saberpoder inherentes a la acumulación del capital (Báez, 2012).

Estas dimensiones deben ser comprendidas de forma dialéctica, es decir, como procesos históricos contradictorios que presentan tensiones desgarradoras de la sociedad donde las resistencias sociales al extractivismo implican mayor violencia por la acumulación del capital. Por ello nos parece importante retomar el concepto de lucha de clases, no en sentido estricto, es decir, como confrontación y contradicción capital-trabajo, sino como la forma que adquiere el conflicto político en el capitalismo global, en este caso capital-sociedad/pueblos.

Cuando mencionamos como primer proceso al reordenamiento territorial en función de la mercantilización de los territorios y su integración a las dinámicas de la acumulación financiera del capitalismo, comprendemos a las formas más visibles del extractivismo: la ampliación de la frontera petrolera, sobre todo la exploración y explotación de petróleo en mar abierto, glaciales, reservas naturales y territorios indígenas; la industrialización de bituminosas y esquisto; la minería a cielo abierto; el agronegocio que incluye pesticidas, transgénicos, monocultivos y sistemas de plantación; los servicios ambientales (que incluye privatización del agua, mercados de carbono, industria del turismo, pago por servicios ambientales); la biotecnología; la geotecnología, los biocombustibles, entre otros. Sin embargo, es muy difícil visualizar, como parte del extractivismo, las reformas académicas y universitarias que se están generando en la región, que en el caso del Ecuador son importantes, o las transferencias monetarias condicionadas desde el Banco Mundial como procesos de control y disciplina social. También es difícil situar al liberalismo y sus nuevas formas, por ejemplo el Estado de derecho y las reformas jurídicas inherentes al extractivismo.

En Ecuador, estos procesos son pertinentes y caracterizan las modalidades extractivas del gobierno de Alianza País y Rafael Correa durante el periodo 2007-2012. 


\section{Ecuador: del Consenso de Washington al} Cambio institucional del Banco Mundial

Para comprender las dinámicas del extractivismo en Ecuador, es necesario establecer una relación entre lo que significó la imposición neoliberal y las reformas institucionales llevadas adelante en el país en 1983-2005. Esta relación es importante porque sitúa las condiciones de posibilidad para la propuesta extractiva en Ecuador.

Ecuador firmó su primera carta de intención con el Fondo Monetario Internacional (FMI) en marzo de 1983, durante el gobierno de Osvaldo Hurtado del Partido Democracia Popular (vertiente de la Democracia Cristiana), y la última fue suscrita en febrero de 2003 por Lucio Gutiérrez del Partido Sociedad Patriótica. En ese periodo se suscribieron 13 cartas de intención con el FMI. La imposición neoliberal del FMI desarticuló la propuesta de industrialización y transfirió el poder político a los grupos económicos vinculados con la agroexportación y el sector bancario y financiero. Estas políticas destruyeron toda solidaridad con el Estado y el sector público, porque significaron empobrecimiento y desempleo generados por la política económica estatal y condujeron a un Estado rentista y patrimonialista y a una clase política adscrita a los principales grupos de poder económico. La relación entre grupos de poder económico y partidos políticos, en este periodo, fue transparente.

En esta coyuntura, Ecuador acentuó el carácter primario de su economía, con altos niveles de concentración del ingreso y una mínima responsabilidad social del Estado, especialmente en salud, educación e infraestructura pública. Durante el periodo de ajuste macrofiscal (1983-2005), la pobreza creció de $35 \%$ en 1973 a $68 \%$ en 1999 . El desempleo y subempleo pasaron de $25 \%$ de la población económicamente activa en 1973 a 55\% en 2006. El gasto público social se redujo de 10\% como porcentaje del PIB en 1972 a 5.5\% en 2002. El sector industrial se redujo de $18.5 \%$ del PIB en 1979 a $12.8 \%$ en 2004. La inversión productiva pasó de $24.7 \%$ del piB en 1978 a 10.43\% en 1999. La de- 
valuación monetaria pasó de 25.4 sucres por dólar en 1980 a 25 mil sucres por dólar en diciembre de 1999 para, finalmente, perder la moneda nacional y pasar a un esquema de dolarización. La inflación que se mantuvo constante en $12 \%$ durante la década de los setenta, producto de las medidas macrofiscales del FMI, se disparó hasta alcanzar 96\% a inicios de 2000. La participación de los salarios de los trabajadores en el рів pasó de 30\% durante la década de los setenta a 7\% en promedio durante la primera década de $2000{ }^{1}$

En abril de 2003, el gobierno de Lucio Gutiérrez suscribió con el Banco Mundial la «Estrategia Asistencia País», para a) consolidar el marco macroeconómico neoliberal en conformidad con las directrices del Consenso de Washington; b) realizar «las necesarias reformas estructurales» para reducir la pobreza, y c) fortalecer la gobernabilidad (Banco Mundial, 2003). Con base en estos objetivos, el Banco Mundial articuló una estrategia de intervención en tres grandes áreas. La primera, denominada «Promoción del crecimiento económico y la competitividad», comprendía los siguientes programas de reforma estructural sectorial: telecomunicaciones, energía e hidrocarburos, transporte, caminos, puertos y aeropuertos, agua, saneamiento, riego y drenaje, investigación y tecnología, comercio y competitividad, mercados financieros y de capitales, agricultura, turismo, producción industrial y protección ambiental. La segunda estrategia, «Reducción de la pobreza e inclusión social», comprendía los siguientes ejes de acción e intervención: educación, capacitación y cultura, salud y población, asistencia social y seguridad alimentaria, seguridad social, género, y pueblos indígenas y afrodescendientes. La tercera estrategia, «Mejorar la gobernabilidad», comprendía modernización del Estado y reforma institucional, descentralización y desarrollo municipal, lucha contra la corrupción, reforma judicial y planificación participativa y diálogo social.

Estas estrategias tenían como objetivo principal la privatización, desregulación, aperturismo, liberalización, descentralización, flexibilización (sobre

/1/ Para las comparaciones estadísticas se han utilizado los datos de las Cuentas Nacionales del Banco Central del Ecuador de varios años. 
todo del mercado laboral y financiero) y estabilización fiscal (es decir, la reducción sistemática y de largo plazo del gasto social y el incremento de impuestos para garantizar el pago de la deuda externa). Para una intervención más eficaz, el Banco Mundial contó con el apoyo del sistema de Naciones Unidas y de la Cooperación Internacional al Desarrollo (Banco Mundial, 2003; Toussaint, 2002; Dávalos, 2010).

La dinámica del ajuste estructural del FMI y de las reformas estructurales del Banco Mundial, del sistema de Naciones Unidas y de la Cooperación Internacional al Desarrollo debilitaron la capacidad de respuesta de la sociedad e impusieron patrones de conducta, de organización y de construcción social desde las lógicas del mercado, el individualismo y la acción estratégica de los actores.

Si bien la sociedad ecuatoriana resistió al ajuste estructural del FMI por la vía de la movilización y la resistencia social, que va desde las huelgas generales convocadas por los sindicatos de obreros durante la década de los años ochenta a los levantamientos indígenas de los años noventa, la «violencia suave», para utilizar un término de Rosa Luxemburg, del Banco Mundial, Naciones Unidas y la Cooperación Internacional al Desarrollo, provocó menos resistencias, menos crítica social y menos movilización, aunque su intervención haya sido más profunda e invasiva.

Los operadores políticos del Banco Mundial, Naciones Unidas y la Cooperación Internacional al Desarrollo emergieron como actores políticos fundamentales durante el gobierno de Alianza País en 2007-2012, y otorgaron una solución de continuidad a las reformas estructurales del Banco Mundial como reformas al sistema político ecuatoriano. ${ }^{2}$ En efecto, no pueden comprenderse

12/ El Ministro de Diálogo y Participación Social del gobierno de Lucio Gutiérrez y hombre de confianza del Banco Mundial, Augusto Barrera, será luego importante cuadro político de Alianza País e incluso llegará a ser alcalde de la capital, Quito, por parte de Alianza País. Gustavo Jalk, hombre del Banco Mundial que dirigió el proyecto Projusticia del Banco Mundial, formó parte del gabinete de Alianza País y dirigió el sistema judicial ecuatoriano. Nathaly Celi es otro personaje importante en Alianza País, fue figura clave del Banco Mundial para armar el mecanismo de Transferencias Mone- 
las dinámicas del extractivismo sin entender el papel fundamental del cambio institucional provocado desde el Banco Mundial. Sin exagerar, puede decirse que las reformas políticas en Ecuador, que empiezan en 2007 con Alianza País, y a pesar del discurso oficial de confrontación con el Banco Mundial y las Instituciones Financieras Internacionales, tienen en los procesos de cambio institucional del Banco Mundial sus condiciones de existencia y posibilidad.

\section{EL DisCURSO POSNEOLIBERAL Y}

\section{EL EXTRACTIVISMO}

La emergencia de Alianza País en las elecciones de 2006-2007 se produce como una consecuencia y una necesidad de relegitimar al sistema político ecuatoriano profundamente desacreditado por la crisis económica, financiera y monetaria de los años 1999-2000. En esa crisis, la clase media ecuatoriana fue devastada porque perdieron sus ahorros monetarios y también perdieron su fe en las instituciones políticas. Fueron esas clases medias desencantadas del neoliberalismo y del sistema político neoliberal las que forman el núcleo duro de la reforma política de Alianza País (Dávalos, 2012). El discurso y la praxis neoliberal perdieron toda credibilidad y legitimidad social. Los sectores medios vieron al neoliberalismo como una amenaza, aunque durante las dos décadas anteriores de ajuste macrofiscal hayan convivido con él y lo hayan considerado como un remedio duro pero necesario para la economía ecuato-

tarias Condicionadas durante el gobierno de Jamil Mahuad (1998-2000). Doris Soliz, figura fundamental de las ong's que acompañaron la reforma sectorial del Banco Mundial, formó parte activa e importante del buró político de Alianza País. Miguel Carvajal formó parte del proyecto Prolocal del Banco Mundial, luego fue ministro de Alianza País y, posteriormente, fue electo asambleísta por este partido. Ricardo Patiño, Ministro del Interior, de Economía y luego canciller del gobierno de Alianza País, estuvo fuertemente vinculado con las propuestas de microfinanzas y desarrollo comunitario en proyectos de ong's financiadas por el BID y del Banco Mundial. Pabel Muñoz, tecnócrata de Alianza País, trabajó en el proyecto mosTA de modernización del Estado y fue consultor de la GTz alemana. 
riana. El resentimiento de las clases medias con el neoliberalismo se produce cuando éste afecta directamente a sus bolsillos y a su capacidad de consumo.

Desde este resentimiento empieza a producirse un discurso crítico con el neoliberalismo, pero connivente con el sistema capitalista. Ese discurso adquiere forma y consistencia política con Alianza País y su líder Rafael Correa. El discurso político de Alianza País es radicalmente crítico con la versión monetarista del ajuste macrofiscal y con el FMi y el Banco Mundial, pero totalmente funcional con las propuestas de cambio institucional del mismo Banco Mundial. Para legitimar esa distancia crítica con el neoliberalismo duro del FMI, se ha propuesto el concepto de posneoliberalismo, como una ruptura radical con la versión monetarista del FMI y del Banco Mundial (Falconí y Muñoz, 2012; Figueroa Ibarra y Cordero Díaz, 2011). Esta crítica ha generado la percepción de que Alianza País es un gobierno de izquierda en contraposición con las imposiciones imperialistas y que genera una política económica y social dentro de un pragmatismo y realismo político. En ese sentido, cuenta a favor de esta agrupación política la recuperación del Estado y el incremento del gasto social (Harnecker, 2012; Gaudichaud, 2011).

Sin embargo, un análisis más detenido de su discurso y su propuesta política permite encontrar vínculos teóricos entre las tesis de cambio institucional de la escuela del neoinstitucionalismo económico — que es el marco teórico de base para las reformas propuestas por el Banco Mundial, el Sistema de Naciones Unidas y la Cooperación Internacional al Desarrollo- y las propuestas políticas de Alianza País. En efecto, uno de los núcleos centrales tanto del discurso y la práctica política de Alianza País es su demanda de «descorporativizar al Estado». Según los teóricos de Alianza País, el Estado ecuatoriano, durante la era neoliberal, fue colonizado por prácticas corporativas que destruyeron el interés general, por ejemplo, los grupos económicos, los sindicatos públicos, los movimientos indígenas. Alianza País se proponía, en consecuencia, eliminar esas prácticas corporativas y «devolver» el Estado a los ciudadanos.

A medida que devolvía el Estado a los ciudadanos, Alianza País también creaba organizaciones sociales desde el propio Estado, porque aquéllas que 
existían habían «abusado» del Estado por medio de prácticas corporativas. Las nuevas organizaciones sociales, creadas y santificadas desde el gobierno, se convertían en apéndices y cadenas de transmisión de la voluntad gubernamental. Aquellas organizaciones que se resistían a ser integradas a la lógica gubernamental podían ser perseguidas o criminalizadas. Las nuevas organizaciones sociales creadas desde el gobierno respondían en forma y fondo a la teoría de la organización del institucionalismo anglosajón.

Ahora bien, detrás de la propuesta de «descorporativizar» al Estado subsumía una demanda estratégica del Banco Mundial, que también partía del mismo criterio teórico: las demandas corporativas generaban «costos de transacción» en la economía que impedían un buen «desempeño económico». Para el Banco Mundial, si el Estado tenía que garantizar la seguridad jurídica a las inversiones, tenía que desprenderse de las prácticas corporativas que lo acosaban y tenía que «reconstruirse». ${ }^{3}$

La intención real del discurso de «descorporativizar» al Estado fue la de desarticular la capacidad política del movimiento indígena ecuatoriano y de su crítica radical al liberalismo. El enemigo real de Alianza País nunca fue el sistema político ecuatoriano y sus partidos políticos, a quienes Alianza País descalificaría como "partidocracia», sino el movimiento indígena, porque éste había situado una praxis de resistencia al neoliberalismo por fuera de los límites liberales de la política. La propuesta de «revolución ciudadana» de Alianza País tenía como objetivo fundamental reducir el discurso emancipatorio del movimiento indígena a los límites del liberalismo decimonónico, porque Alianza País construía las condiciones de su poder y su hegemonía desde ese liberalismo. Al reducir la política a los límites liberales (la «revolución ciudadana»), se estaba acotando de hecho cualquier posibilidad emancipatoria por fuera de esos límites. Ese sistema político liberal, que Alianza País empezó a reconstruir desde su propuesta de «revolución ciudadana», tenía que procesar

\footnotetext{
${ }^{13 /}$ En ese sentido, es fundamental el Informe de Desarrollo Mundial del Banco Mundial (1997).
} 
y continuar las reformas estructurales iniciadas al tenor de las recomendaciones del Banco Mundial, es decir, el extractivismo.

El discurso teórico del extractivismo es aquél de la teoría institucionalista anglosajona de la política, la economía y el derecho. Es un discurso crítico con respecto al neoliberalismo en su versión monetarista, al estilo del FMI, pero siempre en la línea epistemológica de la teoría económica neoliberal. ${ }^{4}$ Los conceptos de la teoría institucionalista - acción colectiva, estabilidad institucional, consenso social y legitimidad, estructura de los incentivos, costos de transacción, asimetrías de la información, selección adversa, racionalidad limitada, votante mediano- se armonizaban con las políticas públicas de Alianza País, en especial la recuperación del papel del Estado en la economía. Incluso uno de los más importantes economistas institucionales, que desde el Banco Mundial había criticado acremente al FMI por su tozudez y terquedad, Joseph Stiglitz, se convirtió en referencia y apoyo importante para el gobierno de Alianza País.

El núcleo teórico central de la teoría anglosajona de las instituciones señala que las sociedades se establecen desde dos procesos básicos: las reglas de juego (formales o informales) que delimitan y estructuran la «acción humana». ${ }^{5}$ Para los institucionalistas las «reglas de juego» formales se codifican en las leyes y el cambio institucional se produce por transformaciones incrementales en lo que ellos denominan «precios relativos». La «acción humana», por su parte, retoma el concepto de uno de los teóricos fundamentales del neoliberalismo: Ludwig Von Mises (2007). ${ }^{6}$ La acción humana es, en realidad, la

/4/ Quizá el ejemplo más claro sea el texto de Stiglitz (2002), que critica al fmi pero, literalmente, desde la vereda del frente, es decir, el Banco Mundial.

15/ «Las instituciones son las reglas de juego en una sociedad o, más formalmente, son las limitaciones ideadas por el hombre que dan forma a la interacción humana. Por consiguiente, estructuran incentivos en el intercambio humano, sea político, social o económico. El cambio institucional conforma el modo en que las sociedades evolucionan a lo largo del tiempo, por el cual es clave para entender el cambio histórico» (North, 2006: 13).

16/ Sobre el papel de Von Mises en el neoliberalismo, puede verse Foucault (2008), el capítulo «Clase del 28 de marzo de 1979 ». 
historización y universalización del concepto de homo economicus creado en el siglo xix por los teóricos de la economía liberal, que serían denominados por Marx como «economistas vulgares».

Ahora bien, para asegurar el crecimiento y mejor desempeño económico es necesario cambiar los incentivos jurídicos generando un ambiente de seguridad jurídica y de respeto a los derechos de propiedad de los inversionistas, pero como los inversionistas y sus inversiones realizan decisiones globales que rebasan el ámbito del Estado-nación, el derecho que los cobija debe también globalizarse. El concepto jurídico que permite la globalización del derecho y que consagra a los inversionistas como figuras de contractualidad es aquél de «Estado de derecho».

De todas las transformaciones institucionales que el Banco Mundial provocó en América Latina, y específicamente en Ecuador, el cambio constitucional del Estado hacia el derecho es quizá uno de los más trascendentes. El concepto de Estado de derecho permite la consolidación de dos procesos claves para el extractivismo: el fortalecimiento de regímenes políticos democráticos por la forma pero autoritarios por su contenido (sistemas políticos hiperpresidencialistas) ${ }^{7} \mathrm{y}$ la globalización del derecho dentro de lo que sería la lex mercatoria.

En el caso de Ecuador, la Constitución de 2008, a pesar de su importante declaración de derechos y garantías, en realidad consolida el monopolio del poder político al interior del ejecutivo y hacia la hegemonía de un solo partido a través del concepto denominado democracia directa. Gracias a esa hegemonía política y al control de todo el sistema político por un único partido político, el extractivismo puede disciplinar la sociedad y, al mismo tiempo, criminali-

17/ El Estado de derecho como tiranía: «Es la producción de un cuerpo de leyes y el desarrollo de un Estado de derecho como la eliminación de la democracia y la total subordinación de los poderes del Estado y los espacios públicos a la cabeza del ejecutivo. En este sentido, se tienen las dos cosas: el mantenimiento de un régimen constitucional, es decir, de legislación según un procedimiento impersonal que tiene como referente la Constitución; por otro lado, hay una concentración del poder político que elimina de facto la separación de poderes y pretende, además, eliminar la autonomía de las instituciones y espacios públicos en el seno de la sociedad civil» (Tapia, 2001: 183, cursivas el original). 
zarla en sus resistencias. No sólo eso, la misma Constitución de 2008 pone en orden de jerarquía, inmediatamente después de ella, a los tratados y convenios internacionales (artículo 425, CPE-2008). Gracias a esa disposición, la Ley Orgánica de la Producción, Comercio e Inversiones aprobada en 2010 establece, en su artículo 18, los derechos de propiedad de los inversionistas y las garantías a la inversión extranjera directa al tenor de las recomendaciones establecidas directamente desde el Banco Mundial y la omc.

En consecuencia, consideramos importante vincular los procesos del extractivismo con los discursos que lo legitiman y lo sustentan, en lo fundamental, el discurso jurídico, económico y político de la teoría anglosajona de las instituciones. A esta vinculación la denominaremos como posneoliberalismo $y$, como es evidente, nada tiene que ver con aquella definición utilizada desde el gobierno de Alianza País y sus corifeos. Entendemos, en consecuencia, al posneoliberalismo como la dinámica de acumulación de capital que continúa la reforma estructural del Banco Mundial, del Sistema de Naciones Unidas y de la Cooperación Internacional al Desarrollo, pero desarticulando la soberanía estatal sobre los territorios y generando un ambiente de confrontación y violencia social que se resuelve por la criminalización y las nuevas formas de terrorismo de Estado. El posneoliberalismo como nueva praxis de la acumulación del capital en América Latina también tiene sus variantes y sus excesos.

\section{EXTRACTIVISMO Y \\ POSNEOLIBERALISMO EN ECUAdor}

Ecuador es una economía primaria que se sustenta en la exportación de petróleo. ${ }^{8}$ Sus exportaciones primarias no petroleras son banano, camarón, flores, cacao y café. El componente de sus exportaciones no primarias, es decir, bie-

18/ Para 2012, las exportaciones de petróleo representaron 20\% del рів de Ecuador, 50\% de las exportaciones y $24 \%$ de los ingresos netos del Estado. 
nes con algún valor añadido, apenas representa $12 \%$ del total de sus exportaciones. $\mathrm{Al}$ interior de su economía, el sector más importante es el sector comercial que absorbe a casi dos tercios de la población económicamente activa. La industria representa apenas $10 \%$ de las actividades económicas totales del país. Al interior del país, alrededor de 60 grupos empresariales controlan $90 \%$ de todas las actividades económicas y tienen un ingreso de aproximadamente $50 \%$ del рів. A pesar de que la pobreza se ha reducido de $68 \%$ en 1999 a $26 \%$ en 2012, el poder de los monopolios y grupos económicos se ha fortalecido, lo que ha implicado un fuerte proceso de concentración y centralización del capital en el mercado ecuatoriano. De otra parte, cabe señalar que en este periodo ha crecido la participación del Estado en la economía, sobre todo por los nuevos marcos institucionales que se han impuesto desde 2007, las reformas tributarias y el mayor peso del gasto fiscal en el PIB, en tal virtud el peso del Estado en la economía para 2012 representó 40\% del PIB.

Es necesario insistir que la economía ecuatoriana sufrió durante dos décadas el ajuste macrofiscal del FMI que redujo a mínimos históricos el gasto fiscal en el sector social y en inversión pública. El gobierno de Alianza País, en cambio, ha provocado un giro radical con respecto al ajuste macrofiscal del FMI, porque ha realizado una importante inversión pública en el sector social y en infraestructura pública, sobre todo en el sector de salud y educación.

El gasto en salud y educación se eleva precisamente a partir del gobierno de Alianza País (2007). La relación con el modelo extractivista es que este incremento del gasto en salud y educación, conjuntamente con la inversión en obra pública, legitima y justifica el discurso extractivo del gobierno de Alianza País. Si la salud y la educación fueran las variables de ajuste durante el periodo de ajuste macrofiscal del FMI, ahora son la variable de legitimidad política para la propuesta extractiva. La cuestión a dilucidar es si efectivamente la renta extractiva del petróleo contribuyó al financiamiento del sector social en Ecuador. Para ello es necesario una visión general de los ingresos fiscales y su relación con los ingresos petroleros, así como los marcos institucionales y jurídicos que determinan el gasto fiscal ecuatoriano. 
En la tabla 1 pueden comprobarse los ingresos fiscales totales de Ecuador durante doce años.

TABLA I

Ingresos fiscales totales. Periodo 2000-2012. En millones de USD.

\begin{tabular}{|c|c|c|c|c|}
\hline \multirow{2}{*}{ Años } & \multirow{2}{*}{$\begin{array}{c}\text { INGRESOS } \\
\text { PETROLEROS }\end{array}$} & \multirow{2}{*}{$\begin{array}{c}\text { INGRESOS FISCALES } \\
\text { PETROLEROS }\end{array}$} & \multicolumn{2}{|c|}{ INGRESOS NO PETROLEROS } \\
\hline & & & IMPUESTOS DIRECTOS & IMPUESTOS INDIRECTOS \\
\hline 2000 & $2.144,0$ & $1.248,8$ & 445,1 & 820,1 \\
\hline 2001 & $1.722,3$ & $1.256,0$ & 434,3 & $1.283,9$ \\
\hline 2002 & $1.839,0$ & $1.324,0$ & 435,2 & $1.497,0$ \\
\hline 2003 & $2.372,3$ & $1.555,4$ & 516,2 & $1.579,6$ \\
\hline 2004 & $3.898,5$ & $1.319,4$ & 605,6 & $1.717,0$ \\
\hline 2005 & $5.396,8$ & $1.574,0$ & 768,9 & $1.966,5$ \\
\hline 2006 & $6.934,0$ & $1.519,2$ & 941,5 & $2.237,3$ \\
\hline 2007 & $7.428,3$ & $1.104,1$ & $1.108,8$ & $2.471,9$ \\
\hline 2008 & $10.568,3$ & $4.400,8$ & $2.338,6$ & $2.824,9$ \\
\hline 2009 & $6.284,1$ & $2.298,2$ & $2.517,5$ & $3.018,5$ \\
\hline 2010 & $8.925,5$ & $3.917,3$ & $2.353,1$ & $3.552,8$ \\
\hline 2011 & $11.799,9$ & $6.682,3$ & $3.030,0$ & $3.960,5$ \\
\hline $2012^{*}$ & $12.715,5^{\star}$ & $5.924,6^{*}$ & $3.081,8^{*}$ & $4.436,4^{\star}$ \\
\hline
\end{tabular}

Fuente: Boletín Estadístico, Banco Central del Ecuador, varios años

Elaboración: autores.

*Para el periodo enero-noviembre 2012

De la tabla 1 pueden extraerse algunas conclusiones. En primer lugar, puede verse la persistencia de una estructura tributaria injusta porque el peso tributario siempre recae en los impuestos indirectos, es decir, aquéllos que afectan la capacidad de consumo de la población y donde su incidencia es más alta mientras menor es el ingreso, de ahí su nombre de impuestos regresivos. Esa injusta e inequitativa estructura tributaria se mantiene durante 2007-2012, que es el periodo de Alianza País. Esta información es pertinente 
porque contribuye a desvirtuar el argumento de que la renta extractiva financia el gasto social. El gasto social siempre estuvo vinculado a los impuestos y quienes finalmente pagaron por el incremento del gasto social en el periodo de Alianza País fueron los más pobres, porque en ellos recaía en mayor medida la responsabilidad fiscal, habida cuenta de que los impuestos regresivos siempre fueron mayores que los impuestos directos.

En segundo lugar, puede constatarse que los ingresos que recibe el Estado por exportaciones de petróleo representaron $14.8 \%$ en 2007 , se incrementaron a $41.6 \%$ en 2008 , luego descendieron a $36.5 \%$ en 2009 , para luego incrementarse a $43.7 \%$ en $2010,56.6 \%$ en 2011 y $42 \%$ en 2012 . Es decir, los cambios en los contratos con las empresas petroleras privadas no significaron en absoluto una mayor participación del Estado en la renta petrolera. Esto significaría que el incremento de los precios de petróleo favoreció en primer lugar a las empresas transnacionales y, en menor medida, al Estado (Villavicencio, 2012).

Por otra parte, es necesario indicar que en el nuevo texto Constitucional del año 2008, el artículo 286 establece la estructura del gasto fiscal, indicando que:

Art. 286.- Las finanzas públicas, en todos los niveles de gobierno, se conducirán en forma sostenible, responsable y transparente y procurarán la estabilidad económica. Los egresos permanentes se financiarán con ingresos permanentes. Los egresos permanentes para salud, educación y justicia serán prioritarios y, de manera excepcional, podrán ser financiados con ingresos no permanentes.

Esto significa que los ingresos por exportación de petróleo crudo no podrán financiar al sector salud y educación, porque representan un gasto permanente. En otros términos, los altos precios de los commodities sólo excepcionalmente pueden financiar al sector social, porque en Ecuador existe una construcción institucional que disciplina de tal manera el ingreso público 
que hace virtualmente imposible que los recursos extraordinarios por los altos precios de los commodities puedan financiar el gasto social. ${ }^{9}$

TABLA 2

Compañías petroleras privadas que operan en la Amazonía Ecuatoriana (continúa).

\begin{tabular}{|c|c|c|c|c|c|}
\hline $\begin{array}{c}\text { Bloque o } \\
\text { CAMpo }\end{array}$ & EMPRESA & Origen & $\begin{array}{l}\text { Estado } \\
\text { ACtUAL }\end{array}$ & $\begin{array}{c}\text { Pueblos } \\
\text { indígenas } \\
\text { Afectados } \\
\end{array}$ & $\begin{array}{c}\text { ÁreASPRotegIDAS } \\
\text { AFECTADAS }\end{array}$ \\
\hline $\begin{array}{l}\text { Bloque } \\
\text { Tarapoa } \\
\text { (Sucumbíos) }\end{array}$ & $\begin{array}{l}\text { Andes } \\
\text { Petroleum }\end{array}$ & China & $\begin{array}{l}\text { Producción, } \\
\text { ampliación de } \\
\text { campos }\end{array}$ & $\begin{array}{l}\text { Siona, Kichwa } \\
\text { Shuar, Colonos }\end{array}$ & $\begin{array}{l}\text { Reserva Faunística } \\
\text { Cuyabeno, Patrimonio } \\
\text { Forestal del Estado }\end{array}$ \\
\hline $\begin{array}{l}\text { Bloque } 11 \\
\text { (Sucumbíos) }\end{array}$ & CNPC & China & & $\begin{array}{l}\text { Cofán, Kichwa, } \\
\text { Shuar, Colonos }\end{array}$ & $\begin{array}{l}\text { Reserva Cofán } \\
\text { Bermejo, Reserva de } \\
\text { la Biosfera Sumaco, } \\
\text { Parque Nacional } \\
\text { Sumaco Napo Galeras, } \\
\text { Área amortiguamiento } \\
\text { de la Reserva Cayambe } \\
\text { Coca }\end{array}$ \\
\hline $\begin{array}{l}\text { Bloque } 16 \\
\text { (Orellana) }\end{array}$ & Repsol-YPF & España & $\begin{array}{l}\text { Producción, } \\
\text { perforación }\end{array}$ & Waorani & $\begin{array}{l}\text { Parque Nacional } \\
\text { Yasuní, } \\
\text { Reserva de la Biosfera } \\
\text { Yasuní }\end{array}$ \\
\hline $\begin{array}{l}\text { Bloque } 18 \\
\text { (Orellana) }\end{array}$ & Petrobras & Brasil & Producción & Kichwa, Colonos & $\begin{array}{l}\text { Reserva de la Biosfera } \\
\text { Sumaco }\end{array}$ \\
\hline $\begin{array}{l}\text { Bloque } 14 \\
\text { (Orellana) }\end{array}$ & Petroriental & China & $\begin{array}{l}\text { Producción, } \\
\text { exploración }\end{array}$ & $\begin{array}{l}\text { Waorani, Kichwa, } \\
\text { Colonos }\end{array}$ & $\begin{array}{l}\text { Parque Nacional } \\
\text { Yasuní, Reserva de } \\
\text { la Biosfera Yasuni. } \\
\text { Patrimonio Forestal } \\
\text { Unidad } 10\end{array}$ \\
\hline $\begin{array}{l}\text { Bloque } 17 \\
\text { (Pastaza) }\end{array}$ & Petroriental & China & $\begin{array}{l}\text { Producción, } \\
\text { exploración }\end{array}$ & $\begin{array}{l}\text { Waorani, Kichwa, } \\
\text { Shuar, Tagaeri- } \\
\text { Taromenane, } \\
\text { Colonos }\end{array}$ & $\begin{array}{l}\text { Área Intangible del } \\
\text { Yasuní, Reserva de } \\
\text { la Biosfera Yasuni, } \\
\text { Patrimonio Forestal } \\
\text { Unidad } 10\end{array}$ \\
\hline
\end{tabular}

19/ En realidad, el artículo 286 de la Constitución ecuatoriana de 2008 recoge y expone un largo proceso de intervención por el FMI y el Banco Mundial sobre el presupuesto público. Ese proceso inició en 
TABLA 2

Compañías petroleras privadas que operan en la Amazonía Ecuatoriana (conclusión).

\begin{tabular}{|c|c|c|c|c|c|}
\hline $\begin{array}{c}\text { BLOQUE o } \\
\text { CAMPO }\end{array}$ & EMPRESA & Origen & $\begin{array}{l}\text { Estado } \\
\text { ACTUAL }\end{array}$ & $\begin{array}{c}\text { Pueblos } \\
\text { INDíGenas } \\
\text { AFECTAdos }\end{array}$ & $\begin{array}{c}\text { ÁreASPRotegidAS } \\
\text { AFECTADAS }\end{array}$ \\
\hline $\begin{array}{l}\text { Bloque } 10 \\
\text { (Pastaza) }\end{array}$ & Agip & Italia & Producción & $\begin{array}{l}\text { Kichwa, Waorani } \\
\text { Zápara }\end{array}$ & $\begin{array}{l}\text { Reserva de la Biosfera } \\
\text { Yasuni }\end{array}$ \\
\hline $\begin{array}{l}\text { Bloque } 23 \\
\text { (Pastaza) }\end{array}$ & CGC & Argentina & $\begin{array}{l}\text { Resistencia de las } \\
\text { comunidades }\end{array}$ & $\begin{array}{l}\text { Kichwa, Achuar } \\
\text { Zápara }\end{array}$ & \\
\hline $\begin{array}{l}\text { Bloque } 24 \\
\text { (Pastaza) }\end{array}$ & Burlington & EEUU & $\begin{array}{l}\text { Resistencia de las } \\
\text { comunidades }\end{array}$ & Shuar, Achuar & \\
\hline
\end{tabular}

Fuente: Acción Ecológica, 2010.

Si esto es así, el discurso gubernamental de financiar el gasto social con extractivismo debe ser considerado más como un recurso ideológico y propagandístico que una realidad. Pero este recurso ideológico es el que utiliza Alianza País para promover las Rondas Petroleras y para entregar concesiones petroleras, incluso en áreas protegidas, como es el caso del Yasuní y los parques nacionales. En los años del gobierno de Alianza País, la frontera extractiva petrolera creció a mayor intensidad que en las dos décadas precedentes. En el siguiente cuadro pueden verse la concesión de los bloques y campos petroleros a empresas privadas durante el periodo 2007-2012.

Las concesiones petroleras, en su mayor parte, están en territorios indígenas y comunitarios. A pesar de la existencia y el reconocimiento jurídico a leyes y derechos que garantizan la posesión efectiva de los territorios por las

1983 con la Ley de Presupuestos y tiene su epítome con la Ley Orgánica de Responsabilidad, Estabilización y Transparencia Fiscal aprobada a fines de 2002, estableciendo varias reglas macrofiscales al tenor de las recomendaciones del FMI. Una de esas reglas macrofiscales es, precisamente, la vinculación del gasto permanente (salud y educación) con ingresos permanentes (impuestos directos e indirectos), recogida por la Constitución de 2008. 
comunidades y pueblos indígenas, así como la defensa de su identidad cultural, la propuesta extractivista de Alianza País ha hecho tabula rasa de esas disposiciones jurídicas en beneficio de las comunidades indígenas. El concepto que ha permitido desarticular las garantías jurídicas que protegen a los pueblos indígenas ha sido, precisamente, aquel del corporativismo. Para Alianza País, la lucha por los derechos, incluida la defensa territorial, es presión corporativa de un grupo restringido que se opone al interés nacional.

\section{GRÁFICO I}

Mapa petrolero de la Amazonía ecuatoriana, año 2012.

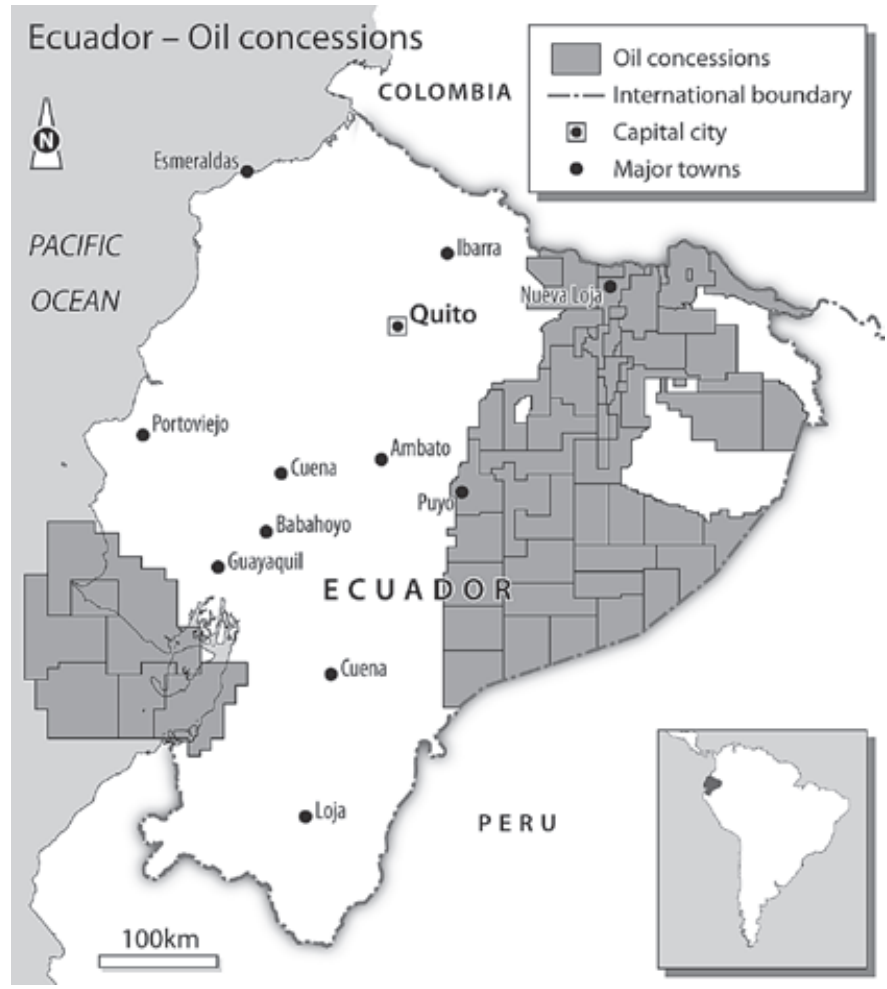

Fuente: Manual de Monitoreo Ambiental, Acción Ecológica, 2012. Elaboración: autores. 
El gobierno de Alianza País considera, en consecuencia, que el interés nacional no se negocia con ningún grupo minoritario que defiende intereses particulares. Si estos grupos de presión, como los considera el gobierno, optan por radicalizar su reclamo y atentan a la propiedad privada, entonces el gobierno tiene que hacer prevalecer el respeto a la propiedad por la fuerza y la violencia de ser necesario; de ahí la criminalización creciente a las organizaciones sociales que se oponen a la entrega de sus territorios al extractivismo petrolero o minero. En la gráfica 1 puede verse que el gobierno de Alianza País prácticamente ha subastado toda la amazonía ecuatoriana a las empresas petroleras.

En el proyecto político de Alianza País puede observarse la coincidencia con los lineamientos estratégicos definidos por el Banco Mundial desde 1997 y el discurso del neoinstitucionalismo económico y político. Un Estado fuerte es la única garantía que existe para la seguridad jurídica a la inversión. Con seguridad jurídica los costos de transacción pueden reducirse al mínimo. Con bajos costos de transacción se puede garantizar un mejor desempeño económico, tal como lo dice la teoría del neoinstitucionalismo económico.

Alianza País, mediante su hegemonía política y su reforma institucional, está construyendo, justamente, un Estado fuerte, en el cual el interés general predomina sobre el interés particular. No obstante, es eso precisamente lo que demandan las empresas extractivas del petróleo, porque un Estado fuerte que asuma directamente su presencia en el área de explotación petrolera puede disminuir los costos de transacción que le significan a las corporaciones extractivas los departamentos de relaciones comunitarias. Si antes de Alianza País las empresas petroleras tenían que comprometerse con la comunidad con obras y con gasto comunitario y tenían que financiar departamentos de relaciones comunitarias, ahora esas tareas las hace directamente el Estado. Las rondas petroleras y la ampliación de la frontera extractiva petrolera, que en otras circunstancias habrían suscitado movilizaciones sociales por organizaciones indígenas, campesinas y de pobladores, porque les expulsaba de sus territorios ancestrales - lo que afectaba la seguridad jurídica y los costos de transacción de las empresas transnacionales que tenían que protegerse con- 
tratando verdaderos ejércitos privados-, ahora puede hacerse directamente desde el Estado. Quien impone las condiciones ya no es la empresa petrolera sino el gobierno y quien defiende a las empresas extractivas ya no son guardias privadas sino directamente el ejército nacional.

Este mismo esquema se repite en la minería abierta a gran escala. Lo que está en juego con la minería no es el excedente que ésta puede generar sino la apropiación de los territorios. Alianza País quiere vincular los territorios a la globalización de la economía. En efecto, en el supuesto de que se mantengan altos los precios de los commodities, en especial los precios de los minerales, y en el supuesto de que los principales proyectos mineros entren inmediatamente en funcionamiento, el máximo de renta minera que el gobierno ecuatoriano podría captar por año sería alrededor de 800 millones de dólares, lo que representa apenas un 6\% de la renta petrolera de 2012, ó $10 \%$ de los impuestos de ese mismo año.

Esos 800 millones de renta minera representarían apenas 1.25\% del PIB de 2012. Como todo proceso extractivo, la minería a gran escala no crea empleo sino que lo destruye. Tampoco incrementa la inversión productiva interna. En cambio, el costo ambiental de esos proyectos mineros es enorme. Si se añade el esquema institucional del gasto fiscal en virtud del cual la Constitución ecuatoriana prohíbe que el ingreso extraordinario, como sería en este caso la renta minera, financie gasto permanente, en especial salud y educación, entonces la renta minera no puede financiar salud y educación ni ningún gasto social.

En el tabla 3 se muestran los principales proyectos de minería a gran escala en Ecuador que tiene previsto desarrollar el gobierno de Alianza País.

La minería acentúa el proceso de reprimarización de la economía, pero más allá de eso permite la vinculación de los territorios a la especulación financiera mundial. Un evento significativo fue la compra de los derechos mineros por la empresa Kinross en 2008, el mismo año en el que el Ecuador discutía y aprobaba un nuevo texto Constitucional en el que se hacía referencia a los nuevos derechos y a la defensa de la soberanía nacional. Mientras la sociedad discutía esos temas, las empresas mineras transaban en los mercados 
financieros los derechos de participación minera sin haber llevado adelante la más mínima inversión, ni haber extraído absolutamente nada y cuando estaba por definirse, precisamente, la Ley Minera y la nueva Constitución. En esa negociación Aurelian Cooper vendió sus derechos mineros en Ecuador por 960 millones de dólares a Kinross. El Estado y la sociedad ecuatoriana, a pesar de sus múltiples referencias a la soberanía nacional, se enteraron de estas negociaciones por informaciones de prensa.

TABLA 3

Principales proyectos de minería a gran escala en Ecuador, año 2012, en USD.

\begin{tabular}{|c|c|c|c|c|c|}
\hline Proyecto & Mirador & $\begin{array}{c}\text { Fruta del } \\
\text { Norte }\end{array}$ & $\begin{array}{c}\text { Panantza } \\
\text { SAN Carlos }\end{array}$ & Río Blanco & Quimsacocha \\
\hline Empresa & Ecuacorriente & Kinross & Explocobres & IMC & INv Metals \\
\hline Ubicación & $\begin{array}{l}\text { Zamora } \\
\text { Chinchipe }\end{array}$ & $\begin{array}{l}\text { Zamora } \\
\text { Chinchipe }\end{array}$ & $\begin{array}{l}\text { Morona } \\
\text { Santiago }\end{array}$ & Azuay & Azuay \\
\hline Material & Cobre & Oro y plata & Cobre & Oro y plata & Oro \\
\hline Método & Cielo abierto & Subterráneo & Subterráneo & Subterráneo & Subterráneo \\
\hline $\begin{array}{l}\text { Regalías e } \\
\text { impuestos por } \\
\text { año \$ USD } \\
\text { millones }\end{array}$ & 164 & 85 & 480 & 15 & 40 \\
\hline $\begin{array}{l}\text { Años del } \\
\text { proyecto }\end{array}$ & 22 & 20 & 25 & 8 & 12 \\
\hline $\begin{array}{l}\text { Procesamiento } \\
\text { anual esperado }\end{array}$ & $\begin{array}{l}215 \text { millones } \\
\text { de lbs. }\end{array}$ & $\begin{array}{l}300 \text { miles } \\
\text { de oz Au } \\
300 \text { miles } \\
\text { de oz Ag }\end{array}$ & $\begin{array}{l}627 \text { millones } \\
\text { de lbs. }\end{array}$ & $\begin{array}{l}531 \text { miles de } \\
\text { oz Au } \\
3 \text { millones de } \\
\text { oz de Ag }\end{array}$ & $\begin{array}{l}200 \text { millones } \\
\text { de oz }\end{array}$ \\
\hline
\end{tabular}

Fuente: Cámara de Minería del Ecuador.

Elaboración: autores.

En la minería lo que interesa no es tanto el mineral cuanto la condición de posibilidad de vincularlo a la emisión de productos financieros complejos. No importa que el mineral haya sido o no extraído, sino que pueda constar en 
el juego especulativo mundial. De hecho, la emisión de productos derivados financieros sobre commodities para junio de 2012 alcanzó la cifra de 2.9 billones de dólares (BIS: 2012). ${ }^{10}$ Los derivados financieros sobre commodities no significan su extracción real ni su movimiento físico, sino las apreciaciones de mercado, las expectativas y su papel de colateral para otras inversiones especulativas. Al incorporar la minería a gran escala al desarrollo nacional, como lo establece el Plan Nacional del Buen Vivir de Alianza País (Senplades, 2009), Ecuador se está vinculando de hecho con los mercados financieros especulativos mundiales.

Pero esta vinculación se está realizando desde los inicios del gobierno de Alianza País, sobre todo con uno de los mercados financieros de más crecimiento y sofisticación, aquél de la industria del carbono. Con un perfil más bajo que el extractivismo petrolero y minero, el mercado del carbono es un mercado en permanente expansión. En efecto, el gobierno de Alianza País ha suscrito todas las estrategias REDD + (reducción de emisiones por deforestación y degradación de bosques) y se ha empeñado en ampliar la frontera extractivista vinculando al país a los mercados de carbono.

Los mercados de carbono son la expresión más evidente del capitalismo de especulación y de las nuevas derivas del extractivismo. Nacieron con el propósito de reducir las emisiones de $\mathrm{CO}_{2}$, reconocidas como las responsables del calentamiento global.

En la lógica de los mercados de carbono, es fundamental situar los «sumideros de carbono» como mecanismos de desarrollo limpio que puedan generar una especie de colateral para las emisiones de derechos de carbono en los mercados financieros internacionales. Según Lohmann, el mercado de carbono tiene una velocidad de crecimiento que lo convierte, conjuntamente con los mercados de derivados financieros, en el mercado especulativo más importante del capi-

/10/ De los cuales, 0.52 billones de USD fueron derivados sobre el oro, 2.4 billones de USD se emitieron en derivados para «otros commodities», 1.6 billones se emitieron en forwards y swaps de commodities, $y$ 0.81 billones de USD se emitieron en options (BIS, 2012). 
talismo actual (Lohmann, 2012). Por su parte, la Conferencia de las Naciones Unidas sobre Comercio y Desarrollo (UNCTAD, por sus siglas en inglés), en una perspectiva neoliberal del clima, ha vinculado los Acuerdos Internacionales de Inversión (AII) con las economías de bajo carbono, mediante un esquema donde se puedan desarrollar marcos normativos favorables que incluyan la creación de mercados de carbono, la ejecución de programas de promoción a los mercados de carbono y «la promoción de inversiones de bajo carbono, las excepciones ambientales, en futuros AII, y un acuerdo multilateral para garantizar la coherencia de los AII existentes con las nuevas políticas mundiales y nacionales relacionadas con el cambio climático» (UNCTAD, 2010:9).

De conformidad con los mercados de carbono y las propuestas de la UNCTAD, se propusieron los mecanismos denominados REDD (Reducción de Emisiones por Deforestación y Degradación de Bosques). El gobierno de Alianza País armonizó las propuestas REDD con su propia versión de los «sumideros de carbono» a través del programa Sociobosque. El régimen ecuatoriano ha suscrito compromisos para conservar cuatro millones de hectáreas de bosque dentro de los programas de sumideros de carbono hasta 2015. Para 2012 se habían suscrito 57 convenios con organizaciones campesinas e indígenas y 574 convenios individuales por 539,703 hectáreas. Muchas tierras comunitarias, entre ellas los páramos que pertenecen a las comunidades indígenas, están dentro de los objetivos de mediano y largo plazo del programa Sociobosque. De hecho, el gobierno de Alianza País ha creado un programa específico para los páramos andinos de propiedad comunitaria; lo ha denominado Sociopáramo. Tanto en Sociobosque como en Sociopáramo, las comunidades son desalojadas de sus tierras y territorios y los contratos suscritos las obligan a convertirse en una especie de guardabosques de sus propios territorios. Al expulsarlos de sus territorios se rompe la dinámica ancestral de convivencia armónica con la tierra y se los convierte en usuarios de una renta monetaria que a la larga termina empobreciéndolos.

Sin embargo, en uno de los aspectos de la dinámica extractivista en los que más ha avanzado Ecuador, es en la realización de proyectos de infraes- 
tructura pública relacionados con la Integración de la Infraestructura para Sud América, irrsa. Para 2007-2011, el gobierno ecuatoriano había realizado inversiones por 5,300 millones de dólares en adecuación de carreteras, caminos, autopistas y rutas de varios niveles. A esta obra física el gobierno de Alianza País la acompañó de una intensiva campaña propagandística que contrastaba las inversiones y obras realizadas con relación a los otros gobiernos.

TABLA 4

Cartera de proyectos IIRSA desarrollados por Ecuador al año 2011 (continúa).

\begin{tabular}{|c|c|c|}
\hline EJE & GRUPO & NOMBRE DEL PROYECTO \\
\hline Andino & G02 & $\begin{array}{l}\text { Implementación del Centro Binacional de Atención de Frontera (СEBAF) en el paso de } \\
\text { frontera Tulcán-Ipiales (Rumichaca). }\end{array}$ \\
\hline Andino & G05 & $\begin{array}{l}\text { Carretera puerto Inca-Huaquillas y puente internacional en Huaquillas-Aguas Verdes, } \\
\text { paso lateral en Huaquillas. }\end{array}$ \\
\hline Andino & G05 & Centro Binacional de Atención de Frontera (севағ) Huaquillas-Aguas Verdes. \\
\hline Andino & G05 & Centro Binacional de Atención de Frontera (CEBAF) Río Mataje. \\
\hline Andino & G05 & Nuevo Aeropuerto Regional de Santa Rosa. \\
\hline Andino & G05 & Proyecto La Espriella-Río Mataje, incluye puente sobre Río Mataje. \\
\hline Andino & G05 & Rehabilitación del tramo Borbón-San Lorenzo (mataje). \\
\hline Andino & G06 & Centro Binacional de Atención de Frontera (CEBAF) San Miguel. \\
\hline Andino & G06 & Construcción de la carretera Zamora-Palanda. \\
\hline Andino & G06 & Mejoramiento y rehabilitación del tramo Bella Unión-Gualaquiza. \\
\hline Andino & G06 & Mejoramiento y rehabilitación del tramo Narupa-Guamaniyacu. \\
\hline Andino & G07 & Centro Binacional de Atención de Frontera (севAF), Puente de Integración. \\
\hline Andino & G07 & Pavimentación Vilcabamba-Puente de Integración-Jaén. \\
\hline Andino & G09 & Armonización regulatoria: eléctrica, gasífera y petrolera. \\
\hline Andino & G09 & Dos microcentrales en Chinchipe y Taguien. \\
\hline Andino & G09 & Extensión del oleoducto nor-peruano. \\
\hline Andino & G09 & Interconexión eléctrica Ecuador-Perú. \\
\hline Andino & G09 & Microcentral en la provincia de Sucumbíos. \\
\hline Andino & G09 & Proyecto interconexión eléctrica Colombia-Ecuador, segunda etapa. \\
\hline Andino & G09 & $\begin{array}{l}\text { Proyecto interconexión eléctrica Colombia-Ecuador, línea } 230 \text { kv entre subestaciones } \\
\text { Pasto (Colombia) y Quito (Ecuador). }\end{array}$ \\
\hline Andino & G10 & $\begin{array}{l}\text { Aprovechamiento de la infraestructura existente y de las nuevas conexiones para } \\
\text { aumentar la infraestructura de comunicaciones. }\end{array}$ \\
\hline
\end{tabular}


TABLA 4

Cartera de proyectos IIRSA desarrollados por Ecuador al año 2011 (conclusión).

\begin{tabular}{|c|c|c|}
\hline EJE & GRUPO & NOMBRE DEL PROYECTO \\
\hline Andino & G10 & Cableado de fibra óptica para telecomunicaciones en redes de transmisión. \\
\hline Amazonas & G01 & Adecuación del puerto de El Carmen. \\
\hline Amazonas & G01 & Adecuación del puerto de San Lorenzo. \\
\hline Amazonas & G01 & Rehabilitación y pavimentación del tramo San Lorenzo-El Carmen. \\
\hline Amazonas & G02 & Centro Binacional de Atención de Frontera (севағ) Nuevo Rocafuerte-Cabo Pantoja. \\
\hline Amazonas & G02 & Construcción del nuevo aeropuerto de Tena. \\
\hline Amazonas & G02 & Implementación del nuevo aeropuerto del Coca. \\
\hline Amazonas & G02 & Puerto de Esmeraldas. \\
\hline Amazonas & G02 & Puerto de Manta. \\
\hline Amazonas & G02 & Puerto de Providencia. \\
\hline Amazonas & G06 & Aspectos ambientales y sociales de las cuencas altas de los ríos amazónicos. \\
\hline Amazonas & G06 & Mejoramiento de la navegabilidad del río Morona, sector ecuatoriano. \\
\hline Amazonas & G06 & Mejoramiento de la navegabilidad del río Napo. \\
\hline Amazonas & G06 & Mejoramiento de la navegabilidad del río Putumayo. \\
\hline Amazonas & G07 & Extensión eléctrica de $22 \mathrm{kv}$ desde proyecto hidroeléctrico Santiago de Morona ( $400 \mathrm{kw})$. \\
\hline Amazonas & G07 & $\begin{array}{l}\text { Mejoramiento de la vía Guayaquil-El Triunfo-La Troncal-Zhud-El Tambo-Cañar- } \\
\text { Azogues-Paute-Amaluza-Méndez y mejoramiento y ampliación del tramo Méndez- } \\
\text { Puerto Morona. }\end{array}$ \\
\hline Amazonas & G07 & $\begin{array}{l}\text { Mejoramiento de la vía Puerto Bolívar-Pasaje-Santa Isabel-Girón-Cuenca-Paute- } \\
\text { Amaluza-Méndez-Puerto Morona. }\end{array}$ \\
\hline Amazonas & G07 & $\begin{array}{l}\text { Mejoramiento de la vía Puerto Bolívar-Santa Rosa-Balsas-Chaguarpamba-Loja- } \\
\text { Zamora-Yantzaza-El Pangui-Gualaquiza-Gral. Leónidas Plaza-Méndez. }\end{array}$ \\
\hline Amazonas & G07 & Nuevo aeropuerto de Puerto Morona. \\
\hline Amazonas & G07 & Paso de frontera sobre el río Morona (Ecuador). \\
\hline Amazonas & G07 & Proyecto hidroeléctrico Morona ( $1 \mathrm{mw})$. \\
\hline Amazonas & G07 & Proyecto hidroeléctrico río Luis. \\
\hline Amazonas & G07 & Proyecto $\mathrm{k} 4$ «Frontera Sur» (acceso a servicios de telecomunicaciones). \\
\hline Amazonas & G07 & Puerto de transferencia de carga morona. \\
\hline
\end{tabular}

Fuente: IIRSA.

El gobierno del Ecuador, a pesar de una supuesta posición antimperialista, nunca ha denunciado a la Iniciativa irrsa. Todo lo contrario, ha formado parte activa de este proceso. Ecuador está atravesado por dos ejes de inte- 
gración y desarrollo de la Iniciativa IIrsa, el Eje Andino y el Eje del Amazonas. Los proyectos del Ecuador en la IIRSA, en virtud de que forman parte de ambos ejes, se han denominado como «proyectos rótula». Para cada eje de integración, Ecuador ha desarrollado también los denominados «proyectos ancla». El proyecto que más atención y desarrollo ha tenido por el gobierno ecuatoriano ha sido el corredor Manta-Manaos.

Dentro de los procesos de convergencia normativa de la Iniciativa IIRSA, el gobierno del Ecuador armonizó sus leyes territoriales y productivas con la Iniciativa IIrsa. Ejemplo de ello son el Código Orgánico de Ordenamiento Territorial Descentralizado (CоотAD, 2010) y el Código Orgánico de la Producción, Comercio e Inversiones, 2010.

Asimismo, el gobierno ecuatoriano ha sido uno de los que más avances ha realizado en obras físicas de acuerdo a la cartera de proyectos de la Iniciativa IIrSA. Hasta 2011, el Ecuador había realizado los proyectos al interior de la IIRSA registrados en la tabla 4.

En la cartera de proyectos IIRSA-Ecuador pueden advertirse varias centrales hidroeléctricas. La mayoría de las centrales hidroeléctricas está relacionada con los proyectos mineros de la región. De esta manera, se integra la concesión territorial a las empresas mineras, la construcción de autopistas - que incluso pueden ser fluviales para que la producción minera pueda incorporarse al mercado mundial一, la construcción de nuevos aeropuertos, la generación de una red energética que soporte el proceso extractivo y los acuerdos legales que garanticen los derechos de propiedad de los inversionistas (convergencia normativa).

Aunque la frontera extractiva en Ecuador cada momento se amplía -incluyendo a transgénicos, ${ }^{11}$ agronegocio, plantaciones de palma africana, plan-

/11/ Luego del triunfo electoral de 2013, que garantiza al Partido Alianza País el control de más de dos tercios de la Asamblea Nacional, las primeras declaraciones del presidente reelecto, Rafael Correa, fueron sus propuestas de cambio constitucional para permitir el uso de transgénicos, que hasta ese momento estaban prohibidos por la Constitución de 2008, así como cambios en la estructura territorial de los municipios y la eliminación de varias de las garantías constitucionales a los ciudadanos (Revista Vanguardia, 2013). 
taciones de Jatropha (o Piñón) para la producción de biodiesel-,$^{12}$ existe un aspecto que hasta el momento no ha sido incorporado al debate sobre el extractivismo a pesar de que es una parte fundamental de éste. Se trata de lo que el pensamiento decolonial llamaría la colonización espistemológica.

Empero, no se trata de un proceso eminentemente teórico sino puramente extractivo. El gobierno de Alianza País tiene la pretensión de crear las condiciones y la infraestructura necesaria para consolidar y expandir aquello que anteriormente se denominaba biopiratería, y que ahora forma parte de los planes de las corporaciones transnacionales de la biotecnología y el agronegocio. El proyecto de la Universidad Yachay, o Ciudad del Conocimiento, ${ }^{13}$ que el gobierno ecuatoriano está construyendo en un valle subtropical a dos horas al norte de la capital, se inscribe directamente en las derivas de la investigación científica de la biotecnología y el agronegocio de transnacionales como Monsanto, Du Pont, Bayer, Syngenta.

La Ciudad del Conocimiento, Yachay, está pensada para articular lo que en la metodología iIrsa (2012) y en la metodología del Banco Mundial-BID se denomina la participación pública-privada (PPP), dentro del campo de la investigación biológica, química, petroquímica y médica. Las investigaciones que se piensan realizar en la Ciudad del Conocimiento, Yachay, están diseñadas en función de la rica biodiversidad que posee Ecuador y de los conocimientos ancestrales de sus pueblos indígenas, sobre todo en el uso de hierbas medicinales. Las investigaciones piensan descubrir los principios activos y moleculares para nuevos fármacos, nuevas aplicaciones químicas y médicas, cosméticos, etcétera, y ponerlas a disposición de las empresas que contribuyan a su financiamiento.

${ }^{/ 12 /}$ El gobierno de Alianza País piensa implementar un proyecto de biodiesel en la provincia costera de Manabí, comprometiendo 50 mil hectáreas. Para el efecto está llevando adelante la construcción de la represa Baba y ha desalojado violentamente a los campesinos del sector.

113/ El Plan Maestro para la Ciudad del Conocimiento «YACHAY» se realiza con la asesoría surcoreana de Incheon Free Economic Zone (Ifez). Ver: 〈http://www.yachay.ec〉. 
El gobierno de Alianza País piensa invertir 20 mil millones de dólares en la Ciudad del Conocimiento, Yachay, en los próximos años y la considera como su propuesta insignia. Esta propuesta expande la frontera extractiva a nuevos niveles y da cuenta de la necesidad de reprocesar el concepto de territorios desde el cual se había venido trabajando teóricamente al extractivismo.

Ahora bien, el avance de la frontera extractiva genera conflicto, confrontación, violencia. La sociedad resiste al extractivismo de diferentes maneras. Desde que empezó el gobierno de Alianza País en 2007, el conflicto social se ha extendido y profundizado. ${ }^{14}$ Ante el incremento del conflicto, el régimen de Alianza País ha optado por una posición de intransigencia, no negociación, imposición, autoritarismo, represión, violencia y criminalización social.

\section{Bibliografía}

BÁEz, René et alt. (2012), Universidades: Entre la mercadofilia y la alterglobalización, Quito, Centro de Pensamiento Crítico-uc.

BIS (2012), вIS Quarterly Review, 4 de junio de 2012, en 〈http://www.bis. org>.

Banco Mundial (1997), Reconstruir el Estado. Informe sobre el Desarrollo Mundial, Washington, Banco Mundial.

(2003), «Informe y recomendación del Presidente del Banco Internacional de reconstrucción y fomento y la Corporación Financiera Internacional para los directores ejecutivos sobre una Estrategia Asistencia País para la República del Ecuador», 29 de abril de 2003, informe número 25817EC. Dávalos, Pablo (2010), La democracia disciplinaria. El proyecto posneoliberal para América Latina, Quito, codeu.

/14/ Se han contabilizado 865 conflictos sociales desde 2007 a 2012. Es el periodo de mayor conflicto social desde el retorno a la democracia en 1979, y mayor que en todo el periodo neoliberal (19822005) (Ecuador Debate, varios años). 
(2011), «Hacia un nuevo modelo de dominación política: violencia y poder en el posneoliberalismo», en Gutiérrez, Raquel (coordinador), Palabras para tejernos, resistir y transformar en la época que estamos viviendo, Oaxaca, Puebla, Pez en el Árbol.

(2012), «Alianza País, las clases medias ecuatorianas y el Ángel de la Historia», Investigación Económica, número 5.

(2013), «Integración y geopolítica: del Consenso de Washington a la Pax Mercatoria», en Sebastián Mantilla y Santiago Mejía (compiladores), Rafael Correa. Balance de la Revolución Ciudadana, Quito, Planeta.

Falconí, Fander y Pabel Muñoz (2012), «Ecuador: de la receta del "Consenso de Washington" al posneoliberalismo», en Sebastián Mantilla y Santiago Mejía (compiladores), Rafael Correa. Balance de la Revolución Ciudadana, Quito, Planeta.

Figueroa Ibarra, Carlos (2011), El recurso del miedo. Estado y terror en Guatemala, Guatemala, F \& G Editores.

Figueroa Ibarra, Carlos y Laura Cordero Díaz (2011), ¿Posneoliberalismo en América Latina? Los limites de la begemonía neoliberal en la región, México, Juan Pablos.

Foucault, Michel (2008), El nacimiento de la biopolítica, México, Argentina, Fondo de Cultura Económica.

Gaudichaud, Frank (coordinador) (2011), El Volcán Latinoamericano. Izquierdas, movimientos sociales y neoliberalismo al sur del Río Bravo, Chile, Ediciones Escapare.

Gudynas, Eduardo (2009), «Diez tesis urgentes sobre el nuevo extractivismo. Contextos y demandas bajo el progresismo sudamericano actual», en Extractivismo, politica y sociedad, Quito, CLAES, CAAP.

Harnecker, Martha (2012), Ecuador: Una nueva izquierda en busca de la vida en Plenitud, Quito, Abya Yala.

Harvey, David (2005), «El"nuevo” imperialismo: Acumulación por desposesión», en Leo Panitch y Colin Leys (editores), El Nuevo desafío imperial. Socialist Register 2004, Argentina, Clacso. 
IIRSA (2012), «Metodologías de Planificación Territorial Indicativa», en 〈http://www.iirsa.org〉.

Lohmann, Larry (2012), Mercados de carbono. La neoliberalización del clima, Quito, Abya Yala.

Luxemburg, Rosa (1978), La acumulación del capital, México, Grijalbo.

North, Douglass (2006), Instituciones, cambio institucional y desempeño económico, México, Fondo de Cultura Económica.

Petras, James (2007), Rulers and Ruled in the us Empire, Atlanta, Clarity Press.

Porto-Gonçalves, Carlos Walter (2009), Territorialidades y lucha por el territorio en América Latina. Geografía de los movimientos sociales en América Latina, Venezuela, Ediciones IVIC.

Saltos, Napoleón (2010), Peaje global: De la hegemonías de usa a la hegemonía de Brasil. Comisión Especial Caso petrobras, Ecuador, ph Ediciones. Senplades (2009), Plan Nacional del Buen Vivir 2009-2013, Quito, Secretaría Nacional de Planificación y Desarrollo.

Stiglitz, Joseph (2002), El malestar en la globalización, Buenos Aires, Taurus. TAPiA, Luis (2011), El Estado de derecho como tiranía, La Paz, Cedes-Ums A. Toussaint, Eric (2002), La bolsa o la vida. Las finanzas contra los pueblos, Donostia-San Sebastián, Tercera Prensa-Hirugarren Prentsa S.L.

UNCTAD (2010), Informe sobre las inversiones en el mundo 2010, Nueva York, Ginebra, Conferencia de las Naciones Unidas sobre Comercio y Desarrollo.

Villavicencio, Fernando (2012), Ecuador Made in China, Quito, Interamerican Institute for Democracy.

Von Mises, Ludwig (2007), La Acción Humana. Tratado de Economía, Madrid, Unión Editorial.

Ziвechi, Raúl (2010), Contrainsurgencia y miseria. Las politicas de combate a la pobreza en América Latina, México, Pez en el Agua. 